\title{
"On the regional impact of broadband on productivity: the case of Brazil"
}




\title{
${ }_{B}^{\mathbb{O}} \mathrm{I}|\mathrm{R}| \mathrm{E}|\mathrm{A}|$
}

Institut de Recerca en Economia Aplicada Regional i Públic

Research Institute of Applied Economics

WEBSITE: www.ub-irea.com•CONTACT: irea@ub.edu

\section{AQR}

\author{
Grup de Recerca Anàlisi Quantitativa Regional \\ Regional Quantitative Analysis Research Group \\ WEBSITE: www.ub.edu/aqr/•CONTACT: aqr@ub.edu
}

\section{Universitat de Barcelona}

Av. Diagonal, $690 \cdot 08034$ Barcelona

The Research Institute of Applied Economics (IREA) in Barcelona was founded in 2005, as a research institute in applied economics. Three consolidated research groups make up the institute: AQR, RISK and GiM, and a large number of members are involved in the Institute. IREA focuses on four priority lines of investigation: (i) the quantitative study of regional and urban economic activity and analysis of regional and local economic policies,

(ii) study of public economic activity in markets, particularly in the fields of empirical evaluation of privatization, the regulation and competition in the markets of public services using state of industrial economy, (iii) risk analysis in finance and insurance, and (iv) the development of micro and macro econometrics applied for the analysis of economic activity, particularly for quantitative evaluation of public policies.

IREA Working Papers often represent preliminary work and are circulated to encourage discussion. Citation of such a paper should account for its provisional character. For that reason, IREA Working Papers may not be reproduced or distributed without the written consent of the author. A revised version may be available directly from the author.

Any opinions expressed here are those of the author(s) and not those of IREA. Research published in this series may include views on policy, but the institute itself takes no institutional policy positions. 


\section{Abstract}

This paper analyses the incidence of broadband on regional productivity in Brazil, intending to find out if the economic impact is uniform across all territories of the country. The possibility of performing a regional approach, instead of the usual country-level analysis, means an opportunity to disentangle the economic impact of broadband at territories which share a common institutional and regulatory framework as are the regions inside a country. Results suggest that the impact of broadband on productivity is positive although not uniform across regions. On the one hand, it seems to depend on connection quality and network effects. Faster download speed and critical-mass accounting for network externalities in the region enhance the economic impact of broadband. On the other hand, higher productivity gains are estimated for the less developed regions. The fact that the less productive regions in Brazil seem to be benefiting more from broadband may suggest that it can constitute a factor favoring regional convergence in the country.

\section{JEL classification: $033,047, \mathrm{R} 11$}

Keywords: Broadband, Information and Communication Technologies, Regional Productivity.

Juan Jung. AQR-IREA, Universitat de Barcelona, Av. Diagonal 690, 08034 Barcelona, Spain. Tel: +34616963716. E-mail: juanjung@gmail.com

Enrique López-Bazo. AQR-IREA, Universitat de Barcelona, Av. Diagonal 690, 08034 Barcelona, Spain. Tel: +34934037041. E-mail: elopez@ub.edu

\section{Acknowledgements}

\footnotetext{
The authors gratefully thank useful comments provided by José María Castellano and José Ignacio Antón. J.Jung acknowledges the award of a Junior Fellowship at the Institut Barcelona d'Estudis Internacionals (IBEI) to research regulation of Information and Communications Technology (ICT) in Latin America, granted by Cátedra Telefónica de Política y Regulación de las Telecomunicaciones e Internet América Latina - Europa.
} 


\section{Introduction}

Information and Communication Technologies (ICT) in general, and broadband in particular, have been extensively studied in the economic literature as a potential source for raising employment and economic growth. There are, however, some gaps in the literature that remain unfilled and that motivate the present research.

In the first place, while the bulk of the literature has focused on either at country-aggregate or firm levels, evidence of subnational-regional analysis of broadband impact on local productivity is still scarce, and mainly limited to the United States. In the second place, those empirical studies that have addressed the regional level usually have replicated the analysis performed at cross-national level, ignoring the regional perspective. For regional analysis, it is a key element to understand if broadband might have a uniform impact on productivity across the regions of a country. In that sense, if the impact of broadband on productivity is found to differ territorially inside a country, then the analysis will have to contemplate the regional dimension, intending to find out why some regions are able to extract more productivity spillovers from technology in comparison with others. The impact of broadband on productivity may depend on a variety of regional attributes, such as the quality of its network infrastructures, the presence of network externalities, and the level of development, among others.

The possibility of working at a regional scale provides some advantages. Country-level analysis is usually affected by important heterogeneities across countries in terms of institutions, culture, regulations, etc. Even if some of these heterogeneities are time-invariant (and as a result can be tackled by fixed effects), others may vary over time. In contrast to the country-level approach, regional analysis provides a more homogeneous framework which allows filtering for those potential heterogeneities and as a result it may allow to measure the impact of broadband on productivity more accurately.

To find out if there are differences in the regional productivity impact of broadband, additional factors will be considered as potential enablers, like connection quality and critical-mass externalities. The possibility of getting homogeneous data on download speeds provides the possibility of considering quality differentials in network infrastructures across regions. A question that motivates this approach is to find out if continuous improvements in speed levels of current connections should also constitute a priority for operators and 
policy-makers, along with universalization.

The empirical analysis focuses in Brazil, which is an emerging country which has reached important economic growth over the last decades, prior to the current political turmoil. A recent report by Centre for Economics and Business Research (CEBR, 2013) forecasted that Brazil will become the world's fifth largest economy in 2023, overtaking UK and Germany. Despite currently facing an economic and political crisis, the country has been able to reduce significantly the levels of poverty since 2000 , combining social policies with economic growth in most of those years. As a result of its potentiality, Brazil has been classified as one of the BRICs (the others being Russia, India and China). A key of this process was the openness of its economy for foreign investment. Since the nineties when many state industries were privatized, the presence of Brazilian multinationals in the world has grown considerably, as well. Its entrance onto the world stage has been reinforced by the high-profile international events that have been hosted in the country: the football World Cup in 2014, and the Olympic Games 2016 in Rio de Janeiro.

Considering the importance of broadband as an essential infrastructure, the Federal Government of Brazil launched the "Programa Nacional de Banda Larga", with the objective of extending the provision of broadband, especially in regions lacking connectivity. The plan, launched at mid-2010, targeted 40 million of connections in a period of 4 years, acting on several fronts, such as expansion of optic fiber networks and price reduction programs, including the implementation of a "popular broadband" tariff for connections of 1 Mbps per 35 Reais per month. Analysis on the implementation of this plan is out of the scope of this paper because it was not until mid-2011 that it started to be implemented in the first towns chosen by the authorities. Despite not being considered in the analysis, the present paper may bring out some inputs to estimate the future economic impact of this initiative across the Brazilian states.

The rest of the paper is structured as follows. The next section reviews the recent literature on ICT and broadband economic impact while section 3 presents a theoretical framework that serves as the basis for the econometric analysis in this study. The dataset and variables used in the analysis are introduced in section 4 and described in section 5. The results of the estimation of the effect of broadband on regional productivity are presented and discussed in section 6 . Finally, section 7 briefly summarizes the main conclusions of the work, with 
some remarks and policy implications.

\section{Literature review}

The economic impact of infrastructures has been widely studied in the economic growth literature, following the initial contribution of Aschauer (1989), who included public capital as a productivity determinant. The impact of telecommunications infrastructure has also been studied, being Roller and Waverman (2001) an important contribution in the field. The diversity of channels through which ICT can contribute to productivity and economic growth has been extensively studied in the literature (for a complete review see, for instance, Cardona et al, 2013).

In the last few years most of ICT-derived contributions to productivity has come from the development of broadband high-speed internet connections, which has been classified as a General Purpose Technology (GPT) by some authors (Mack and Faggian, 2013; Czernich et al, 2011). Because of its attributes, they state that the new technologies influence productivity beyond the effect of regular capital goods. According to Mack and Faggian (2013) and Jordan and De Leon (2011), broadband now constitutes a key part of the necessary infrastructure for development, in the same way as oldest types of infrastructures such as railroads, roads and electricity.

Recent empirical analysis has mainly concentrated on analyzing the broadband impact on economic growth. Czernich et al (2011) studied a sample of 25 OECD countries for the period 1996-2007 and found that a 10\% increase in broadband penetration raises annual growth in GDP per capita by $0.9-1.5$ percentage points. Koutroumpis (2009) studied a sample of 22 OECD countries for the period $2002-2007$, finding that a $10 \%$ increase in broadband penetration contributed to $0.25 \%$ in GDP growth. For a sample of 120 countries, Qiang et al (2009) found that a $10 \%$ increase in broadband penetration contributed to more than $1 \%$ of increase in GDP per capita growth. As it can be seen, most empirical analyses focus on the broadband incidence on GDP growth rather than on productivity.

At a regional level, research has been much scarcer, and mostly referred to the United States. For instance, Crandall et al (2009) studied the effects of broadband deployment on output and employment in US states for the period 2003-2005. They found a positive association of employment and broadband use in several 
industries, but were unable to find a significant association between output and broadband. Mack and Faggian (2013) analyzed the regional impact of broadband provision for US counties, finding that it had a positive impact on productivity only when accompanied with high skills. Lehr et al (2005) studied the impact of broadband at US communities, finding out a positive impact of broadband on economic growth.

An ongoing debate in the literature is related to the link between the new technologies and underdeveloped regions. It is believed that ICTs may open possibilities for isolated regions to overcome traditional disadvantages associated to their remote location. As a result, new technologies and internet diffusion could reduce the role played by agglomerations. Some authors even talk about the "death of distance" as a result of an eventual widespread deployment of ICT services (Cairncross, 2001). According to this view, distance would be less important and peripheral regions would benefit from opportunities that were not available before (Bonaccorsi et al, 2005; Quah, 2000; Kelly, 1998; Negroponte, 1995).

In some cases, the presence of broadband infrastructure facilitates the development of poor regions, enhancing some degree of territorial equilibrium (Suriñach et al, 2007). Isolated regions may present some advantages as lower wages and housing costs, which can be fully exploited if good broadband infrastructure is available. In that case, it can attract companies to locate in these regions, especially those which can suffer from congestion costs in more developed regions, increasing demand and activity in isolated areas. This might lead to a positive spiral of increased activity that may help even people who is not a user of broadband.

Even if not related to regional analysis, Thompson and Garbacz (2011) find that broadband has a relatively more favorable economic impact in low-income countries than in high-income countries. Similarly, Qiang et al (2009) suggested that the growth effects of broadband, as well as those of other technologies, were higher in low-income countries than in high-income economies. According to Fernández-Ardèvol et al (2011), the economic impact of mobile phones was larger in Latin America than in OECD countries.

Conversely, other authors argue that the economic impact should be bigger in high income economies. For instance, for a country-level analysis, Katz (2012) stated that economies with lower internet penetration tend to exhibit a lesser 
contribution of broadband to economic growth. The reason for this statement is linked to network externalities resulting from larger broadband penetration. This critical-mass effect might lead to increasing returns to broadband penetration. Other authors argue that ICT can exacerbate disparities between regions, both within and across countries, because regions may differ not only in ICT endowments, but also in the possibilities to make a productive use of it (Gareis and Osimo, 2004). Billón et al (2009) argue that agglomerations and internet may be complementaries rather than substitutes. According to Bonaccorsi et al (2005), disparities and inequalities seemed to be reinforced, rather than reduced, by ICT diffusion. Along with that, the importance of complementarities (i.e., ICT and human capital), sectoral composition and institutional framework may contribute to a higher economic impact in more developed economies. At the same time, the decrease of the role of distance as a result of the new technologies may be over-optimistic, referred to earlier, as only codified knowledge can be transmitted through ICTs, meaning that for tacit knowledge diffusion distance will remain to be relevant.

A relatively unstudied aspect of broadband impact is that related to differences in the quality of the infrastructure (proxied by downloading speed). A recent paper by Rohman and Bohlin (2013), based on a sample of 34 OECD countries during the period 2008-2010, suggests that doubling the broadband speed contributes to $0.3 \%$ growth compared with the growth rate in a base year. They performed its estimates in two stages in order to tackle concerns regarding reverse causality between broadband speed and output. The relevance of quality is explained because low transmission capacity and speed of dial-up internet severely limit access to content-dense applications. Howell and Grimes (2010) argue that fast internet access is considered a productivity-enhancing factor. As a result, quality of connections should also be considered as a potential factor which may contribute to regional differences in the economic impact of broadband.

All the previous arguments may give an insight that broadband should have a positive impact on productivity, and that the impact may be different across regions, even inside the same country. The possibility of performing the analysis in a big country as Brazil, which exhibits important regional inequalities, may provide a better understanding of the regional dimension of the impact of broadband in productivity, and may contribute to evaluate its suitability as an instrument for regional cohesion in emerging economies. 


\section{Theoretical framework and empirical specification}

In this section we build our model on the basis of an augmented Solow (1956) framework, where economies are supposed to produce according to a Cobb-Douglas production function with various input factors:

$$
Y_{i t}=A_{i t} K_{i t}^{\alpha} L_{i t}^{\beta} H_{i t}^{\gamma}
$$

$Y$ represents output, $K$ is physical capital stock, $L$ is labour and $H$ denotes human capital, approximated as $H=e^{h}$, where $h$ reflects the efficiency of a unit of labour, in a similar fashion as Hall and Jones (1999). Subscripts $i$ and $t$ denote respectively regions and time periods. The term $A$ represents Total Factor Productivity (TFP), which reflects differences in production efficiency across regions over time. TFP can be expressed as:

$$
A_{i t}=\Omega_{i t}(X) B B_{i t}^{\Phi}
$$

TFP is stipulated to depend on some region-specific characteristics, represented by $\Omega(X)$, a term which is influenced either by a vector of control variables $X$, varying across regions and over time, and by time invariant idiosyncratic productivity effects, which may make some regions more productive per se because of unobserved characteristics. As it is supposed that broadband contributes to increase productivity, and to facilitate the development of new products and processes, and the adoption of new technologies devised by others, $A$ is assumed to depend positively on the level broadband infrastructure denoted by $B B$. The stock of broadband infrastructure is used, instead of investment, because users demand infrastructure and not investment per se (Koutroumpis, 2009). A positive value for $\Phi$ is expected indicating the productivity gains derived from broadband.

The empirical specification will be derived omitting the subscripts for region and time period for the sake of simplicity. The lack of available data for state-level physical capital stocks in Brazil require of some assumptions and rearrangements to derive a workable empirical specification. Adopting the assumption that markets are competitive, capital earns its marginal product (Romer, 2006), and thus firms in this economy will acquire physical capital until its marginal productivity equals its price, usually approximated by the real interest rate $r$ :

$$
\frac{\partial Y}{\partial K}=A \alpha K^{\alpha-1} L^{\beta} H^{\gamma}=r
$$


From this expression, the demand for physical capital can be derived as:

$$
K=\left[\frac{\alpha A L^{\beta} H^{\gamma}}{r}\right]^{\frac{1}{1-\alpha}}
$$

Inserting the derived demand for physical capital in [1], yields an expression for output which do not depends on physical capital on the right-hand side:

$$
Y=A\left[\frac{\alpha A L^{\beta} H^{\gamma}}{r}\right]^{\frac{\alpha}{1-\alpha}} L^{\beta} H^{\gamma}
$$

Under the assumption of constant returns to scale for physical capital and labour ${ }^{2}$, $\alpha+\beta=1$, the previous expression can be easily manipulated to obtain a measure of labour productivity which does not depend on the stock of physical capital:

$$
\frac{Y}{L}=\frac{\alpha^{\left[\frac{\alpha}{1-\alpha}\right]} A^{\left[\frac{1}{1-\alpha}\right]} H^{\gamma\left[\frac{1}{1-\alpha}\right]}}{r^{\left[\frac{\alpha}{1-\alpha}\right]}}
$$

Inserting the expression for TFP in [2] and log-linearising results in:

$$
\log \left[\frac{Y}{L}\right]=\left[\frac{1}{1-\alpha}\right] \log \alpha+\left[\frac{1}{1-\alpha}\right] \log \Omega(X)+\left[\frac{1}{1-\alpha}\right] \Phi \log B B+\left[\frac{1}{1-\alpha}\right] \gamma h-\left[\frac{\alpha}{1-\alpha}\right] \log r
$$

The interest rate is easily assumed to be the same across the regions because financial markets are integrated inside the country. Similarly, it is assumed as constant as the long-term rate is supposed to vary little over the time period analyzed. ${ }^{3}$ Renaming the constant factor $\Gamma_{0}=\left[\frac{1}{1-\alpha}\right] \log \alpha-\left[\frac{\alpha}{1-\alpha}\right] \log r$, and the following parameters successively as $\Gamma_{i}$, the empirical specification can be written as:

$$
\log \left[\frac{Y}{L}\right]=\Gamma_{0}+\Gamma_{1} \log \Omega(X)+\Gamma_{2} \log B B+\Gamma_{3} h
$$

As a result, the empirical specification relates labour productivity to broadband, human capital, and some controls. The parameter $\alpha$ cannot be identified from the empirical specification, so the figure for the physical capital share in income from the Brazilian national accounts will be used to recover the structural parameters associated to broadband: $\Phi=\Gamma_{2}(1-\alpha){ }^{4}$

\footnotetext{
${ }^{2}$ This assumption has been made before in empirical research for the Brazilian case (see for instance da Silva Filho, 2002)

${ }^{3}$ In any case, any difference will be absorbed by the region fixed effects.

${ }^{4}$ It is important to note that this implies a return to physical capital which is common to all regions. Lack of constraints in the inter-regional mobility of capital in Brazil favours such assumption, although severe differences in the industrial mix could lead to cast some doubts
} 
The previous specification is a sort of baseline empirical model that is useful to obtain a common-regional measure of the impact of broadband on productivity, but is inappropriate to explore the existence of differences across regions in the impact. As a result, the empirical exercise in this paper will consider further strategies which will require of slight modifications to the TFP term expressed in [2]. On the one hand, the economic impact of broadband may vary depending on other characteristics of the infrastructure, such as the quality of the connection, and the presence of network externalities. Similarly, as stated in the literature review, broadband may have a different impact depending on the degree of economic development of the region. To explore these matters, we will consider a more general expression for [2] to account for heterogeneities in the effect of broadband on productivity:

$$
A=\Omega(X) B B^{\left(\delta_{0}+\delta_{1} Z\right)}
$$

where $Z$ refers to the set of factors which may have an incidence on the economic impact of broadband, to be defined on course, and the vector of parameters $\delta_{1}$ reflects the incidence of the other factors in interaction with broadband. The procedure to derive the empirical specification and the strategy for recovering structural parameters is similar to that indicated in the baseline model.

The availability of a panel data set for the Brazilian states allows to account for region fixed effects, or in other words to control for time-invariant unobserved region characteristics. As a result, the pernicious influence of confounding factors omitted in the specification (e.g. the effect of geography and differences across regions in managerial talent that evolves smoothly over time) is less a concern in our empirical exercise. Still, a common critique of ICT and broadband estimations is that the results could determine correlation rather than a causal effect on productivity, because investment in ICT may be considered as a driver, but also a result of productivity and economic growth (Cardona et al, 2013). This likely reverse causality may arise because individuals and firms in high-income economies may also have higher resources to pay for broadband. Some authors exploit the structure of panel data by using lagged variables for ICT (Bloom et al, 2010; Hempell, 2005; Tambe and Hitt, 2001; Brynjolfsson and Hitt, 1995). Other strategies may be structural multi-equation models (Röller and Waverman, 2001; Koutroumpis, 2009), and Instrumental Variables estimation (IV), with a first-stage diffusion equation (Bertschek et al, 2013; Czernich et al, 2011). In this

under imperfect inter-sectoral mobility. This issue will be further discussed in section 6 . 
study, we take the latter approach. ${ }^{5}$

Bertschek et al (2013) firm-level analysis uses ADSL availability as an instrument for broadband. Their results suggested that the IV approach resulted in higher coefficients for broadband incidence in productivity, although less precise than OLS as the standard errors increase, leaving the broadband coefficient as weakly significant. In Czernich et al (2011) country-level analysis uses fixed-line voice telephony and Cable TV pre-existing networks as instruments for broadband. Its estimations suggested that IV results are slightly larger than OLS, concluding that OLS regressions are downward biased.

Following Czernich et al (2011), in the empirical exercise we will build on the idea that most common broadband roll-out (i.e.: ADSL or Cable Modem) rely on the copper wire of pre-existing voice-telephony networks. As stated by Czernich, the required access to an existing infrastructure built for other purposes, such as that of fixed telephony, make this a suitable instrument for this estimation strategy. The instrument in this case is the number of voice-telecommunication fixed access lines per 100 inhabitants with a five-year lag. In addition, as broadband deployments may depend on demographic factors, population density will be added as instrument, but using variables from the beginning of the last century (census performed between years 1920 and 1950). The instruments were lagged considerably to break any possibility of being affected by contemporary shocks. That is to say, to guarantee that the exclusion restriction are meet which implies that the measure of density does not affect in a direct way the region's productivity but only indirectly through its effect on $B B$.

\section{Dataset and variables}

To test the effect of broadband connections on regional productivity, this study estimates the key parameters of the empirical model sketched in the previous section using data from the 27 Brazilian states (including Brasilia D.F.) in the period from 2007 to 2011 . Table 1 provides the precise definition and source of the key variables to be used in the empirical analysis. As for the dependent variable, labour productivity is computed as the ratio of gross value added (GVA) to employment in each state and year. GVA, that subtracts intermediate

\footnotetext{
${ }^{5} \mathrm{We}$ decided not to use lagged values of the broadband measure due to the high persistence in this variable.
} 
inputs from the gross output, is usually considered a more accurate measure of the actual surplus created by the regional economy (Cardona et al, 2013). The data, extracted from the Instituto Brasileiro de Geografia e Estatística (IBGE) database, is deflated to 2000 constant Reais prices. Data for the workforce, total number of workers in each state, comes from the Instituto de Pesquisa Econômica Aplicada (IPEA) database. For cases of missing 2010 employment information, interpolation using data for 2009 and 2011 was used to fulfill the gaps.

Regarding the key variable in the study, broadband, some preliminary comments are in order. Considering the importance of ICT to increase the competitiveness of territories, inequalities detected in its diffusion can have implications for economic growth, human development and the creation of wealth (Vicente and López, 2011; Billón et al, 2009; ITU, 2006). One of the consequences of the lack of broadband connections is that it generates a new divide between those who have access to a large number of applications, for which broadband is needed, and those who do not have access (Billón et al, 2009).

A wide definition of digital-divide includes a large number of technology-related variables. Nevertheless, given the scope of the paper the empirical analysis focus on broadband only. There is no public regional data on firms' broadband adoption in Brazil. But, as stated by Vicente and López (2011), firm adoption is expected to be highly correlated with the overall spread of broadband across the entire population. As a result, penetration across inhabitants is used in our empirical analysis. In this regard, it should be stressed that several contributions to the extant literature have used penetration levels to approximate broadband infrastructure (see, for instance, Koutroumpis, 2009, and Czernich et al, 2011).

Broadband is defined as internet access provided at a certain high level of speed capacity (considering the standards for the period under analysis). In Brazil, most internet available at the end of the 90s and beginning of the 2000s were based on slow dial-up connections, which imposed restrictions for its usability and ability to make full use and take full advantage of internet applications. The introduction of broadband allowed the possibility of exploiting internet full potential. The $\mathrm{OECD}^{6}$ in 2006, and the International Telecommunications Union (ITU) ${ }^{7}$ in 2007 defined broadband as those internet connections with speeds above $256 \mathrm{Kbps}$. In

\footnotetext{
${ }^{6} \mathrm{http} / / /$ www.oecd.org/sti/broadband/oecdbroadbandstatisticstodecember2006.htm

${ }^{7}$ https://www.itu.int/ITU-D/ict/material/IndDef_e_v2007.pdf
} 
this case, Telebrasil (the Brazilian Association of Telecommunications) classified internet connections by speed considering a threshold of $512 \mathrm{Kbps}$. Therefore, for the purpose of this research, only broadband connections that reach at least $512 \mathrm{Kbps}$ or more were considered for the study. In our opinion this constitutes a much more realistic approximation for broadband than that based on a threshold of $256 \mathrm{Kbps}$, which hardly served for the most advanced applications during the period under analysis. As a result, Broadband is defined as the number of connections above the $512 \mathrm{Kbps}$ threshold per 100 inhabitants in the region.

As for human capital, it is proxied by the literacy rate, which despite being a measure of the basic skills of the population, is appropriate in our study as they are far from being universal in the case of the Brazilian regions ${ }^{8}$.

Finally, as stated before, TFP is assumed to depend on some region-specific characteristics. Most of them may surely constitute time invariant regional features, such as idiosyncrasy, culture, geographic location, climate, natural resources, etc. Therefore, region fixed effects are expected to capture all those components of unobserved heterogeneity which may make some regions more productive than others. Beyond that, to control for further productivity differences across regions, a number of variables were considered. In the first place, $R \& D$ activities have been identified in the literature as relevant to foster productivity (Romer, 1990; Grossman and Helpman, 1991; and Aghion and Howitt, 1992). For regional analysis, however, introducing an $R \& D$ variable can be problematic, as many firms whose research labs are located in some regions may have production facilities distributed through the rest of the country, which would also benefit from that research (De la Fuente, 2002). Having said that, we will include the percentage of R\&D expenditures of the regional governments in relation to its GVA, which can also be interpreted as a proxy for absorptive capacity, as well as a measure of innovation-prone environment. In the second place, as Coe and Helpman (1995) pointed out, TFP may depend not only on domestic R\&D, but also on foreign $R \& D$, with those spillovers becoming stronger the more open an economy is to foreign trade. Considering trade activity as an important source of foreign technological spillovers, we will add a variable

\footnotetext{
${ }^{8}$ As stated by Caselli (2005), more conventional measures of human capital as data on years of schooling for population over 25 years old may seem appropriate for developed countries with a large share of college graduates, but it is not appropriate for most developing countries. In order to proxy for more advanced skill levels than literacy rate, we also considered to add school enrollment from the population aged between 15 and 17 years old (lagged 5-years), but its coefficient was always insignificant while the main results remained unchanged.
} 
measuring imports as a percentage of regional GVA.

In further estimations, to take into account additional sources of heterogeneity, we will include measures of the sectoral composition of the economy, represented as the percentage of agriculture and services across the whole regional GVA. Following De la Fuente (2002), we will also consider the unemployment rate, in order to proxy any cyclical component which may affect productivity.

\section{Descriptive analysis}

Descriptive statistics for labour productivity, the measure of broadband, and the regional controls are shown in Table 2 . It is observed that important differences arise in labour productivity levels across regions, appearing Brasilia D.F. as the highest-productivity region. Brasilia presents some peculiarities. It was founded in 1960, in order to move the capital from Rio de Janeiro to a more central location. The difference in productivity levels between Brasilia and its most close followers (Rio de Janeiro and Sao Paulo) is substantial, possibly related to differences in its sectoral composition (its main economic activities are services and public administration) and on the fact that Brasilia is a city in a small federal district, while the other regions constitute states. On the other side, the lowest productivity region is found in Piauí, with a GVA per worker in 2011, which accounted for only $14 \%$ of that of the capital city, and $30 \%$ of that of Rio and Sao Paulo.

Figure 1 summarizes territorial disparities in labour productivity in Brazil at the initial and final years of the period analysed. While there is not a clear core-periphery pattern of the regional distribution of productivity, most lagged regions appear to be concentrated in the Northeast. On the other side, most productive regions seem to be located at the Southeast (Rio de Janeiro, São Paulo, Espírito Santo), while there are some centers of development in the South (Rio Grande do Sul) and in the Northwest (especially Amazonas). Amazonas is an industrial state, which has attracted considerable exporting industries in the last decades. Under a scheme of tax incentives, through the duty-free zone in Manaus, Amazonas has attracted manufacturing companies of cell-phones, electronics and motorcycles, among others.

Some of the fastest growing areas in the period are those in low-productive 
regions in the Northeast (with the exception of Bahia), which may suggest that some process of convergence was in place. Despite that, the spatial pattern seems to be persistent, with the relative positions remaining almost unchanged between 2007 and 2011. The reason may be that a possible convergence process can take much longer than the analyzed period in this research.

The description of Broadband in Table 2 reveals that penetration averaged 3 subscriptions per 100 inhabitants across the 5-year sample, being again Brasilia the one which reaches the highest level in 2011, with a penetration of 15.47 (almost $50 \%$ of its households). There seems to be a considerable regional digital-divide, as poor states, such as Amapá, reached a broadband penetration of only 0.19 in 2011 (less than $1 \%$ of households). This feature is confirmed by the maps reported in Figure 2. In fact, there even seems to be a more pronounced spatial pattern in the case of broadband than for regional productivity. The highest penetrations levels are observed in Brasilia and the Southern regions, while Northern regions appear to be lagging behind in terms of connectivity (the Amazonas forest is likely to be the reason behind the lower infrastructure deployment in some states in this area). As a remarkable element, the lagged northeastern regions appear to reach in some cases acceptable levels of connectivity. It is worth noting that Billón et al (2009) report a similar pattern for European regions, as internet adoption followed an uneven spatial distribution with arising agglomeration centers. In a similar fashion, Bonaccorsi et al (2005) state that both developed and developing countries suffer from serious regional disparities in ICT.

The descriptive evidence provided so far for the level of productivity and the measure of broadband suggests marked regional disparities in both magnitudes. A first insight into the link between them for the Brazilian states can be derived from Figure 3, that plots the regional values of Broadband vis-à-vis those of productivity. Despite correlation should not be read straightforwardly as evidence of a causal effect going from broadband connection to productivity, it indicates a strong positive association between the two variables. That is, productivity and the amount of broadband penetration tend to appear together in the set of Brazilian regional economies. The next section provides estimates of this link net of the effect of other regional characteristics that could confound the simple relationship between the two variables depicted in Figure 3. As deduced from the description of the measures of human capital and the regional controls in Table 2 , there are also substantial disparities across the Brazilian regions in other potential 
determinants of productivity, that should be taken into account when assessing the effect of broadband on regional productivity.

\section{Results}

\subsection{Baseline specification}

This section presents and discusses the results of the estimation of the effect of broadband on productivity in the Brazilian regions, using the specifications described in section 3. As mentioned in that section, it is not possible to identify $\alpha$ directly from the estimated coefficients. To do so, additional information on the capital share in income from the Brazilian economy is used. In that sense, Feenstra et al (2015), using the Penn World Table data (PWT), find that the labour share in the income of Brazil averaged 0.55 in the period 2007-2011. Under the assumption of constant returns to scale, this implies $\alpha=0.45$, value that will be used to recover the structural parameter of interest. Table 3 reports estimates of the baseline model that assumes no interaction between broadband penetration and regional attributes.

Column (i) in Table 3 reports the Ordinary Least Squares (OLS) results for the baseline model. The coefficient of Broadband is found to be highly significant and sizeable in magnitude. The implied estimated effect, $\Phi$, suggests that a $10 \%$ increase in broadband penetration improved regional productivity by $0.2 \%$. To assess the magnitude of this effect is worthwhile taking into consideration that the overall average of Broadband in the sample is 3 connections per 100 inhabitants, the $10 \%$ increase represents moving that value up to 3.3 connections per 100 inhabitants. As for the estimate of the coefficients of the other regressors, it is obtained a positive and significant (at 5\%) effect of the literacy rate on productivity. This suggests that differences in the endowment of basic skills in the population contribute to explaining productivity disparities among brazilian regions. On the other hand, conditional to the other observable and unobservable regional characteristics, public spending in $\mathrm{R} \& \mathrm{D}$ as a percentage of the region's GVA do not exert a significant effect on productivity. In contrast, the effect of the relative amount of regional imports is positive and significant, which suggests that more open regions benefit from foreign R\&D embodied in traded goods and, as a result, tend to be more productive.

Although the magnitude of this estimate of the effect of broadband penetration is 
similar to that in other empirical studies in the literature, additional estimations will be performed to evaluate its robustness. In the first place, column (ii) in Table 3 includes additional regressors, with the aim of controlling for the existence of further regional specific differences in $\Omega$. Particularly, three additional variables are included: the sectoral composition (percentages of agricultural and services activities in local GVA) and the unemployment rate, as a proxy for any cyclical component which may affect productivity. Results in column (ii) reveal that only the coefficient of the share of services in total GVA is statistically significant and, most importantly, that the inclusion of these controls does not alter the results for the estimated effect of Broadband. In other words, the estimate of its impact is robust to the addition of further controls in the regional production function.

As discussed in section 3, the OLS estimator will provide biased estimates of the effect of Broadband if it is an endogenous regressor. To account for this possibility, columns (iii) and (iv) in Table 3 report the results based on an IV estimator using the instruments discussed in section 3. In both cases, the statistic of the overidentifying restrictions test fails to reject the null hypothesis of exogeneity of the instruments. On the other hand, the weak instruments test rejects that the instruments are weakly correlated with the broadband measure. Therefore, it can be concluded in favour of the validity of the instruments used. The IV estimated coefficient of Broadband in column (iii) is only marginally smaller than that reported by OLS. To be clear, it remains positive although decreases somewhat its significance (significant at a $5 \%$ level) as a result of a slight decrease in the size of the coefficient and also a small increase in the standard error. In any case, the implied effect of broadband derived from the IV estimation points to a substantial effect of broadband on the region's productivity (a $10 \%$ increase in fast broadband penetration raises regional productivity by $0.17 \%)$. As with the OLS, the estimated effect of Broadband remains unchanged when further control variables are included (column iv). Overall, these results provide support to the hypothesis that fast broadband intensification cause a positive impact on the level of productivity of the Brazilian regional economies. ${ }^{9}$

\footnotetext{
${ }^{9}$ As mentioned at the beginning of this section, the effect of Broadband on productivity is estimated using the value of the share of capital in income deduced from the data in the PWT for the entire Brazilian economy (0.45). Alternatively, it is possible to compute the share of capital in income for each Brazilian state for 2010 and 2011 from the Brazilian Regional Accounts. The results obtained in that case are shown in Table A.2 in the Appendix. It is observed that the estimated effect for the entire country is somewhat smaller in this case due to
} 


\subsection{Regional heterogeneity in the effect of broadband}

Once the impact of broadband on the productivity of the Brazilian regional economies has been verified, it seems interesting to assess whether the impact is uniform across states or if, on the contrary, it varies with some characteristics of the infrastructure and with the level of development of the territorial units. With this aim, the empirical model is modified to accommodate the TFP function in equation [2']. In the first place, it is assumed that there is a certain critical-mass required to get benefits from network externalities. To be clear, the TFP function in $\left[2^{\prime}\right]$ is specified as:

$$
A=\Omega(X) B B^{\left(\delta_{0}^{M}+\delta_{1}^{M} \text { Mass }\right)}
$$

where Mass is a binary variable defined as a function of a given threshold of broadband penetration: it equals 1 for regions with level of penetration above the threshold, and 0 otherwise. To define the threshold, it should be taken into account that even the lowest thresholds considered in previous studies for OECD countries were found to be far above from the Brazilian standards during the period under analysis. ${ }^{10}$ Therefore, after analysing the distribution of the values of the variable, a minimum threshold of $6 \%$ penetration is adopted, a level which means approximately $20 \%$ of households with broadband connection. ${ }^{11}$ Under this specification, regions in which penetration was below this threshold are supposed to get no productivity gains of increases in Broadband. It is when reaching the threshold that improvements in Broadband start leading to higher productivity in the region. Therefore, we expect $\delta_{1}^{M}>0 .{ }^{12}$

Another important aspect that could shape the impact of broadband on regional productivity is the existence of differentials in the quality of connections. To approximate quality, following Rohman and Bohlin (2013), the measure to be used is the average speed of connections in the region. Available data from Telebrasil allows considering differences in average bandwidths across regions. Broadband download average speed is constructed with data which classifies

\footnotetext{
the highest share of capital in this alternative source. In any case, these results reveal some important differences across regions, with the estimated effect ranging from 0.010 in Espirito Santo to 0.018 in Amapá.

${ }^{10}$ For instance, Koutroumpis (2009) considers as critical the threshold of $20 \%$ penetration per inhabitant, while Czernich et al (2011) measure network externalities from a 10\% level.

${ }^{11}$ The average size of Brazilian households is 3.2 persons.

${ }^{12} 16 \%$ of the observations in the sample are above the threshold (Mass $=1$ ). The percentage increased over the analysed period from $0 \%$ in 2007 to $37 \%$ in 2011.
} 
subscriptions to different groups depending on its speed. More precisely, average speed for each interval were weighted by the corresponding penetration levels $\mathrm{s}^{13}$. The description of this variable, Quality, is in Table A.3 and Figure A.1 of the Appendix.

In this case, the specification of equation [2'] is as follows:

$$
A=\Omega(X) B B^{\left(\delta_{0}^{Q}+\delta_{1}^{Q} Q u a l i t y\right)}
$$

The moderating effect of the average quality of connections in the region is hypothesised to be positive, i.e. $\delta_{1}^{Q}>0$. In other words, for two regions with the same relative amount of broadband connections, we expect to observe a higher impact on productivity for the region with the higher average speed.

The results of the IV estimation of the parameters of the specifications allowing for these types of heterogeneities in the effect of Broadband are reported in the first block of columns in Table $4 .{ }^{14}$ In both cases, two groups of instruments have been used to account for the interaction between the corresponding variable (Mass or Quality) and (the log of) Broadband. In the first place-columns (i) and (iii)-, the interaction between the variable and the two instruments used before are added to the list of instruments. This assumes that Mass and Quality are exogenous regressors. Since the instruments based on the interactions would not be appropriate if Mass and Quality are endogenous, we also report results that exclude the interactions from the list of instruments -columns (ii) and (iv).

As expected, the estimate of the coefficient for the interaction between Mass and Broadband, $\delta_{1}^{M}$, is positive, although it is only statistically significant at $10 \%$ when just the two original instruments are used. This result confirms that there is a threshold above which further penetration of broadband leads to improvements

\footnotetext{
${ }^{13}$ Telebrasil offers data on fixed broadband connections across the following speed intervals: (1) 512 Kbps - 2 Mbps; (2) 2 Mbps - 34 Mbps; and (3) higher than 34 Mbps. The formula for computing average download speed for region $i$ at time $t$ is: Qualityit $=1.25^{*}[B B(1) i t]+18^{*}[B B(2) i t]+50^{*}[B B(3) i t]$, where $B B(i)$ refer to share of connections in speed interval $i(=1,2,3)$. Assigned speed values for intervals (1) and (2) correspond to the mean of the corresponding interval. Speed for the interval (3) is right-censored, and the election of $50 \mathrm{mbps}$ is somewhat arbitrary, although results are not sensible to different approximations. The equivalence formula is $1 \mathrm{Mbps}=1024 \mathrm{Kbps}$.

${ }^{14}$ Only the specification that does not include the sector and unemployment controls is considered in this subsection given that their addition to the list of regressors does not modify the estimate of the key parameters. The corresponding results are available upon request.
} 
in regional productivity, whereas this is far from guaranteed below the threshold (the estimated effect for regions below the threshold, i.e. Mass $=0$, is not statistically significant).

As for the moderating effect of quality, results confirm the hypothesis that the impact of Broadband is increasing with the average speed in the region. At the overall average speed in the sample, the implied $\Phi$ is estimated at 0.022 , whereas it takes a value of 0.013 and 0.050 at the minimum and maximum values of speed, respectively. That is two say, the impact of broadband on productivity is fourfold in the region with the highest average speed with respect to the one in the region in which the average speed was the lowest. This confirms that quality of the connection matters for the impact of broadband on productivity. ${ }^{15}$ As in the case of the interaction involving Mass, there is a decrease in the significance of the coefficient of the interaction when only the original instruments are used. This seems to be caused by the higher standard error as the magnitude of the coefficient remains the same in the two estimations.

Finally, we explore the relationship between the size of the effect of Broadband and the level of development in the region. The hypothesis is that more peripheral regions, with lower density of economic activity and, thus, less developed, may obtain higher productivity gains from broadband connections as this technology will allow economic agents in that regions to keep away from some of the costs of peripherality, making location in the region more attractive for production. To test this hypothesis, regions are classified in three groups according to the level of development, measured through the average GVA per worker in the period under analysis. The composition of the three groups is shown in Table 5. Based on this classification, binary variables were created to identify the regions belonging to each group ( $L P, M P$ and $H P$ for low-, medium-, and high-productive, respectively).

Using this information, the specification of equation [2'] is defined as:

$$
A=\Omega(X) B B^{\left(\delta_{H P}+\delta_{M P} M P+\delta_{L P} L P\right)}
$$

where $\delta_{H P}$ measures the effect of Broadband for the group of most developed regions, and that for the other two groups is obtained by adding the

${ }^{15}$ Consistent with the specification, the estimate of the coefficient of $\log$ (Broadband) in columns (iii) and (iv) is not statistically different from zero. This is the expected effect when the average speed in the region is zero. 
corresponding parameter, $\delta_{M P}$ or $\delta_{L P}$. A conspicuous way of checking the hypothesis under analysis is testing that $\delta_{M P}=\delta_{M P}=0$.

The last column in Table 4 summarises the results of the IV estimation of this specification. They confirm that important differences among regions do in fact exist, and that they are linked to the level of development. All regions benefit from fast broadband, but the less developed appear to obtain much larger productivity gains through broadband than medium and highly developed regions. To be clear, the increase in regional productivity induced by increasing broadband penetration by $10 \%$ is estimated to be $0.19 \%$ and $0.15 \%$, respectively, in the groups of regions with high and medium levels of development, while it raises up to $0.43 \%$ in the group of the less developed Brazilian regions. Therefore, on average, these results suggests that the impact of broadband on productivity is particularly high for regional economies with low levels of productivity and, therefore, of development, and declines to about the half as regions become more developed. Overall, these results support the hypothesis in this paper about the regionally differentiated impact of broadband on productivity.

\section{Conclusions}

This paper has aimed to provide robust evidence on the impact of broadband on productivity in Brazil and, particularly, on the fact that these effects are not uniform across the territory. In fact, broadband seems to be yielding higher productivity gains for regions which exhibit a minimum threshold of penetration levels (providing evidence of network effects), as well as regions with higher quality in its internet infrastructures, denoted by the broadband speed. Moreover, further analysis provided evidence of a higher effect of broadband on productivity for less developed regions. However, due to data unavailability, we were unable to contrast other possible sources of regional heterogeneity in the impact of broadband on productivity, which may explain why less developed regions are extracting more benefits from this technology. A complete understanding of those aspects should have to be addressed in future research.

Even if a convergence analysis remained out of the scope of this paper, our results suggest that broadband connectivity might constitute a factor favoring regional cohesion in Brazil. In the past, Barrios et al (2008) find that ICT 
investments have contributed significantly to regional convergence in Spain. They also state that the development of ICT activities constitute a potentially good candidate for promoting regional development. In the same line, Ding et al (2008) suggest that telecommunication infrastructure contributed significantly to regional convergence in China, supporting investment policies in telecom in lagged regions of developing countries. They state that facilitating telecommunications infrastructure is important for assisting economic growth in the least developed regions of developing countries with poorly developed telecom infrastructure. To confirm that assertion for the case of Brazil, further research will be required, especially when long enough time series data is available to perform a long-term growth-regression analysis.

In any case, broadband connectivity appears to be a source of productivity gains in Brazil, something that provides empirical support to the recently deployed public program of connectivity "Programa Nacional de Banda Larga".

To conclude, some policy implications can be derived from the analysis. The importance of broadband for regional development makes that all levels of government should implement policies that encourage broadband deployment. Although referring to the case of Europe, Barrios and Navajas (2008) state the importance to adopt, together with country-level initiatives, regional policies, because the nature of technological change and innovation have a strong regional component that make that public policies must be designed taking the regional dimension into account. In Brazil, some states have started to follow this strategy, as for instance Paraná and Amapá, which have launched state-based broadband public plans, as aiming to complement the above-mentioned national plan. Barrios and Navajas (2008) highlight the importance that regional cohesion policies consider the relevance of ICT infrastructure, aiming to favor the attractiveness of less developed regions. They even call for differentiated intervention, even among regions within a country. Regional policies should also promote ICT skills and the use of ICT by small and medium size enterprises (Barrios et al, 2008).

In this context, investment from service providers in broadband infrastructure is critical, both in terms of coverage and speed. As stated by Crandall et al (2009), it is essential that regulatory policies do not reduce investment incentives for carriers. In particular, policymakers should adopt measures that promote, or at least do not inhibit, the growth of broadband. In density-populated areas, private 
competition will surely provide the required incentives which will lead to higher investments and better connectivity. In those markets, it will be necessary from federal and state governments to reduce entry barriers and promote investment by incumbents and new service providers. In contrast, in distant areas, with low levels of population and economic density, or affected by adverse geographical conditions, public intervention will definitely become vital for infrastructure deployment. At those cases, universalization policies might become crucial. As stated by Frieden (2005), broadband investment requires of important levels of public and private cooperation. The results in this paper prove that the return to these policies is likely to be quite high.

Policy will also need to promote connectivity from the demand-side. Lower prices are necessary to increase penetration, because, as stated by Galperin and Ruzzier (2013), broadband demand is elastic. Promoting flexibility in commercial offers, as well as tax reductions for low-income segments, and small-low productive firms, may constitute feasible alternatives to tackle affordability barriers. Additionally, to maximize demand and social returns to broadband deployment, policymakers should address eventual ICT-related skills among the workforce.

Downloading speed is, as seen before, relevant to enhance the economic impact of broadband, and it will probably become more important in the future, as data traffic through the networks is increasing and will start to strain current infrastructures.

Although not addressed by this research, mobile broadband may also constitute an opportunity to close the digital-divide, especially through its potential to connect isolated distant areas (Katz, 2012). In that sense, spectrum allocations will be required to provide necessarily resources for deployment of new generation services as LTE and 5G. 


\section{References}

Aghion, P. and Howitt, P. (1992) A model of growth through creative destruction, Econometrica, 60, 323-51.

Aschauer, D.A. (1989) Is Public Expenditure Productive? Journal of Monetary Economics, 23, 177-200.

Barrios, S. and Navajas, E. (2008) The location of ICT activities in EU regions. Implications for regional policies, Investigaciones Regionales 13, 179-2010.

Barrios, S., Mas, M., Navajas, E., and Quesada, J. (2008) Mapping the ICT in EU regions: location, employment, factors of attractiveness and economic impact.

Bertschek, I., Cerquera, D. and Klein, G. (2013) More Bits - More Bucks? Measuring the Impact of Broadband Internet on Firm Performance, Information Economics and Policy 25, 190-203.

Billón, M., Ezcurra, R. and Lera-López, F. (2009) Spatial effects in website adoption by firms in European regions, Growth and change, 40(1), 54-84.

Billón, M., Marco, R. and Lera-López, F. (2009) Disparities in ICT adoption: A multidimensional approach to study the cross-country digital-divide, Telecommunications Policy, 33(2009), 596-610.

Bonaccorsi, A., Piscitello, L. and Rossi Lamastra, C. (2005) The ICT Diffusion: A Spatial Econometric Approach. SSRN eLibrary.

Brynjolfsson, E. and Hitt, L.M. (1995) Information technology as a factor of production: the role of differences among firms. Economics of Innovation and New Technology, 3(3), 183-200.

Cairncross, F. (2001) The death of distance: how the communications revolution will change our lives, Harvard Business School Press, Cambridge, MA, USA.

Cardona, M., Kretschmer, T. and Strobel, T. (2013) ICT and productivity: conclusions from the empirical literature, Information Economics and Policy, 25, 109-125. 
Caselli, F. (2005) Accounting for cross-country income differences, Handbook of economic growth, 1, 679-741.

Coe, D.T. and Helpman, E. (1995) International r\&d spillovers, European economic review, 39(5), 859-887.

Crandall, R.W., Lehr, W., and Litan, R.E. (2007) The effects of broadband deployment on output and employment: a cross-sectional analysis of US data. Brookings Institution.

Czernich, N., Falck, O., Kretschmer, T. and Woessman, L. (2011) Broadband infrastructure and economic growth, The Economic Journal, 121(552), 505-532.

da Silva Filho, T.N.T. (2002) Estimating brazilian potential output: A production function approach. BCB Documento de trabajo, 17.

De la Fuente, A. (2002) On the sources of convergence: A close look at the Spanish regions, European Economic Review, 46(3), 569-599.

Ding, L., Haynes, K.E. and Liu, Y. (2008) Telecommunications infrastructure and regional income convergence in China: panel data approaches. The annals of regional science, 42(4), 843-861.

Feenstra, R.C., Inklaar, R. and Timmer, M.P. (2015) The Next Generation of the Penn World Table. American Economic Review, 105(10), 3150-3182.

Fernández-Ardèvol, M., Galperin, H., and Castells, M. (2011) Comunicación móvil y desarrollo económico y social en América Latina. Barcelona, Spain: Ariel, Fundación Telefónica.

Frieden, R. (2005) Lessons from broadband development in Canada, Japan, Korea and the United States, Telecommunications Policy, 29(8), 595-613.

Galperin, H. and Ruzzier, C.A. (2013), Price elasticity of demand for broadband: evidence from Latin America and the Caribbean. Telecommunications Policy, 37(6), 429-438.

Gareis, K. and Osimo, D. (2004) Benchmarking regional performance in the Information Society: turning it into practice. In Workshop "Measuring the information society: what, how, for whom and what.

Grossman, H.I., and Helpman, E. (1991) Innovation and growth in the global 
economy, Cambridge, MA: MIT Press.

Hall, R.E. and Jones, C.I. (1999) Why Do Some Countries Produce so much more Output per Worker than Others, Quarterly Journal of Economics, 114(1): 83-116.

Hempell, T. (2005) What's spurious, what's real? Measuring the productivity impacts of ICT at the firm-level, Empirical Economics 30(2), 427-464.

Howell, B. and Grimes, A. (2010) Feeding a Need for Speed or Funding a Fibre 'Arms Race'? Communications and Strategies, 78, 127-45.

International Telecommunication Union (2006) World telecommunication/ICT development report 2006. Measuring ICT for social and economic development. Geneva: ITU.

Jordán, V. and de León, O. (2011) Broadband and the digital revolution. In: Fast-tracking the digital revolution: Broadband for Latin America and the Caribbean, Edited by V. Jordán and H. Galperín, 13-48. Santiago, Chile: United Nations.

Katz, R. (2012) Impact of broadband on the economy. Broadband series. Telecommunication Development Sector. International Telecommunications Union.

Kelly, K. (1998) New rules for the new economy. Ten ways the network economy is changing everything, Fourth Estate, London, UK.

Koutroumpis, P. (2009) The economic impact of broadband on growth: a simultaneous approach, Telecommunications Policy, 33(9), 471-485.

Lehr, W.H., Osorio, C.A., Gillett, S.E., and Sirbu, M.A. (2005) Measuring Broadband's Economic Impact, Tepper School of Business, Paper 457.

Negroponte, N. (1995) Being Digital, Knopf, New York, NJ, USA.

Mack, E. and Faggian, A. (2013) Productivity and Broadband: The Human Factor, International Regional Science Review, 36(3), 392-423.

Qiang, C.Z.W., Rossotto, C.M. and Kimura, K. (2009) Economic impacts of broadband. Information and Communications for Development 2009: Extending Reach and Increasing Impact, World Bank, Washington DC (2009) (pp. 35). 
Quah, D. (2000) Internet cluster emergence, European Economic Review, 44(4-6), 1032-1044.

Rohman, I.K. and Bohlin, E. (2012) Does broadband speed really matter as a driver of economic growth? Investigating OECD countries, International Journal of Management and Network Economics, 2(4), 336-356.

Röller, L.H. and Waverman, L. (2001) Telecommunications infrastructure and economic development: a simultaneous approach, American Economic Review, 91(4), 909-923.

Romer, D. (2006) Advanced Macroeconomics, McGraw Hill, New York.

Romer, P.M. (1990), Endogenous technological change, Journal of Political Economy, 98, S71-S102.

Solow, R. (1956) A contribution to the theory of economic growth, Quarterly Journal of Economics, 70: 65-94.

Suriñach, J., Romaní, J. and Termes, M. (2007) ¿Afecta la banda ancha al crecimiento económico? Evidencia sobre agentes y territorio, Investigaciones regionales, 10, 207-235.

Tambe, P. and Hitt, L.M. (2011) The Productivity of Information Technology Investments: New Evidence from IT Labor Data. SSRN eLibrary.

Thompson, H.G. and Garbacz, C. (2011) Economic impacts of mobile versus fixed broadband. Telecommunications Policy, 35(11), 999-1009.

Vicente, M.R. and López, A.J. (2011) Assessing the regional digital-divide across the European Union-27, Telecommunications Policy, 35(2011), 220-237. 
Table 1. Variables used in the empirical analysis

\begin{tabular}{llc}
\hline \multicolumn{1}{c}{ Variable } & \multicolumn{1}{c}{ Definition } & Source \\
\hline Labour productivity & $\begin{array}{l}\text { Gross Value Added per worker in Reais at } \\
2000 \text { constant prices }\end{array}$ & $\begin{array}{c}\text { Computed using data from } \\
\text { IBGE and IPEA }\end{array}$ \\
Broadband & $\begin{array}{l}\text { Number of subscriptions }(>512 \mathrm{Kbps}) \text { per 100 } \\
\text { inhabitants }\end{array}$ & Telebrasil \\
Literacy rate & Literacy rate of population over 15 years old & IPEA \\
Public R\&D intensity & $\begin{array}{l}\text { Percentage of R\&D expenditures of state } \\
\text { governments in relation to their GVA }\end{array}$ & $\begin{array}{c}\text { Ministério da Ciência, } \\
\text { Tecnologia e Inovação } \\
\text { Ministério da Indústria, } \\
\text { Comércio Exterior e } \\
\text { Serviços }\end{array}$ \\
Agriculture & Imports as a percentage of GVA & IBGE \\
Services & Percentage of sectoral GVA & IBGE \\
Unemployment & Percentage of sectoral GVA & IBGE \\
\hline Snemployment rate &
\end{tabular}

Source: Author's elaboration

Table 2. Descriptive statistics

\begin{tabular}{|c|c|c|c|c|}
\hline Variable & Mean & Min & Max & Obs \\
\hline \multirow{2}{*}{ Labour product. } & 14490.230 & 5180.351 & 46762.560 & \multirow{2}{*}{135} \\
\hline & {$[7371.611]$} & (Piauí, 2007) & (Distrito Federal, 2010) & \\
\hline \multirow{2}{*}{ Broadband } & 2.972 & 0.040 & 15.470 & \multirow{2}{*}{135} \\
\hline & [3.210] & (Amapá and Roraima, 2007) & (Distrito Federal, 2011) & \\
\hline \multirow{2}{*}{ Literacy rate } & 88.249 & 74.260 & 96.850 & \multirow[t]{2}{*}{135} \\
\hline & [6.291] & (Alagoas, 2008) & (Distrito Federal, 2009) & \\
\hline \multirow{2}{*}{ Imports } & 0.082 & 0.000 & 0.484 & \multirow{2}{*}{135} \\
\hline & {$[0.090]$} & (Acre, 2008) & (Amazonas, 2008) & \\
\hline \multirow{2}{*}{ Public R\&D int. } & 0001 & 0.000 & 0.006 & \multirow{2}{*}{135} \\
\hline & {$[0.001]$} & (Rondônia, 2009) & (Sao Paulo, 2011) & \\
\hline \multirow{2}{*}{ Agriculture } & 0.091 & 0.000 & 0.290 & \multirow{2}{*}{135} \\
\hline & {$[0.067]$} & (Distrito Federal and Rio de Janeiro) & (Mato Grosso, 2008 - 2009) & \\
\hline \multirow{3}{*}{ Services } & 0.313 & 0.220 & 0.470 & \multirow{3}{*}{135} \\
\hline & & (Acre,2007; Amazonas and Pará, & & \\
\hline & {$[0.055]$} & 2010) & (São Paulo, 2011) & \\
\hline \multirow{2}{*}{ Unemployment } & 8.521 & 3.600 & 16.300 & \multirow{2}{*}{135} \\
\hline & [2.429] & (Santa Catarina, 2011) & (Amapá, 2007) & \\
\hline
\end{tabular}

Note: standard deviation in brackets 
Table 3. Estimation of the baseline model

\begin{tabular}{|c|c|c|c|c|}
\hline Estimation & (i) & (ii) & (iii) & (iv) \\
\hline \multirow{2}{*}{$\operatorname{Iog}($ Broadband $)$} & $0.037 * * *$ & $0.036 * * *$ & $0.030 * *$ & $0.030 * *$ \\
\hline & [0.013] & {$[0.012]$} & {$[0.015]$} & {$[0.013]$} \\
\hline \multirow{2}{*}{ Literacy rate } & $0.022 * *$ & $0.022 * *$ & $0.024 * * *$ & $0.024 * * *$ \\
\hline & {$[0.008]$} & {$[0.008]$} & {$[0.008]$} & {$[0.008]$} \\
\hline \multirow{2}{*}{ Imports } & $0.599 * *$ & $0.545^{* *}$ & $0.608 * *$ & $0.545 * *$ \\
\hline & {$[0.242]$} & {$[0.246]$} & {$[0.239]$} & {$[0.231]$} \\
\hline \multirow{2}{*}{ Public $R \& D$ intensity } & -0.327 & -0.262 & -0.334 & -0.261 \\
\hline & {$[0.258]$} & {$[0.274]$} & {$[0.225]$} & {$[0.228]$} \\
\hline \multirow{2}{*}{ Agriculture } & & -0.189 & & -0.213 \\
\hline & & {$[0.444]$} & & {$[0.420]$} \\
\hline \multirow{2}{*}{ Services } & & $-1.024 * *$ & & $-1.021 * * *$ \\
\hline & & {$[0.470]$} & & {$[0.367]$} \\
\hline \multirow{2}{*}{ Unemployment } & & -0.000 & & -0.001 \\
\hline & & {$[0.005]$} & & {$[0.004]$} \\
\hline Implied $\Phi$ & 0.020 & 0.020 & 0.017 & 0.017 \\
\hline Observations & 135 & 135 & 132 & 132 \\
\hline R-squared & 0.643 & 0.670 & 0.537 & 0.572 \\
\hline Method & OLS & OLS & IV & IV \\
\hline Weak identification test & & & 62.183 & 60.239 \\
\hline Over-id test statistic & & & 1.731 & 2.598 \\
\hline \multicolumn{5}{|c|}{$\begin{array}{l}\text { Note: }{ }^{*} p<10 \%,{ }^{* *} p<5 \%,{ }^{* * *} p<1 \% \text {. Robust standard errors in brackets. All estimates include region fixed effects. } \\
\text { Instruments for Broadband in IV: telephone fixed voice lines per } 100 \text { inhabitants (lagged } 5 \text { years), and population density at } \\
\text { the beginning of the XX century (census 1920-1950). First step estimates for columns (iii) and (iv) in Table A.1 are in the } \\
\text { Appendix. Stock-Yogo weak identification test critical values: } 8.68 \text { (10\% maximal LIML size). }\end{array}$} \\
\hline
\end{tabular}


Table 4. Estimation allowing for regionally heterogenous effects

\begin{tabular}{|c|c|c|c|c|c|}
\hline Estimation & (i) & (ii) & (iii) & (iv) & (v) \\
\hline \multirow{2}{*}{$\log$ (Broadband) } & 0.025 & 0.015 & 0.009 & 0.008 & $0.034 * * *$ \\
\hline & {$[0.016]$} & {$[0.018]$} & {$[0.017]$} & {$[0.021]$} & {$[0.013]$} \\
\hline \multirow{2}{*}{ Mass $* \log ($ Broadband $)$} & $0.015^{* *}$ & $0.027^{*}$ & & & \\
\hline & {$[0.008]$} & [0.015] & & & \\
\hline \multirow{2}{*}{ Quality*log(Broadband) } & & & $0.003^{* * *}$ & $0.003 *$ & \\
\hline & & & {$[0.001]$} & {$[0.002]$} & \\
\hline \multirow{2}{*}{$L P^{*} \log ($ Broadband $)$} & & & & & $0.044 * * *$ \\
\hline & & & & & {$[0.016]$} \\
\hline \multirow{2}{*}{$M P * \log ($ Broadband $)$} & & & & & -0.007 \\
\hline & & & & & [0.019] \\
\hline Implied $\Phi[\min , \max ]$ & $\begin{array}{c}0.014 \\
0.022]\end{array}$ & $\begin{array}{l}0.008, \\
0.023]\end{array}$ & $\begin{array}{l}0.013, \\
0.050]\end{array}$ & $\begin{array}{l}0.012, \\
0.050]\end{array}$ & \\
\hline Implied $\Phi H P$ & & & & & 0.019 \\
\hline Implied $\Phi L P$ & & & & & 0.043 \\
\hline Implied $\Phi M P$ & & & & & 0.015 \\
\hline Weak identification test & 27.117 & 8.782 & 12.969 & 11.157 & 7.083 \\
\hline Over-id test statistic & 2.298 & - & 0.004 & - & 3.377 \\
\hline
\end{tabular}

Source: Author's analysis from the databases described above.

Note: Estimations corresponding to the IV method. Instruments as in Table 3, with the addition of their interaction with the Mass or the Quality variables in (i) and (iii). First step estimates available upon request. The number of observations is 132 in all cases. $*_{p}<10 \%$, **p<5\%, $*^{* *} p<1 \%$. Robust standard errors in brackets. LP and MP denote dummy variables for low-and medium-productive regions, respectively. The omitted category is the group of high-productive regions. All specifications include region fixed effects and as control variables the Literacy rate, Imports, and Public R\&D intensity. The "-" denotes that the Over-id test statistic is not available for the corresponding estimates as the number of instruments equals that of endogenous regressors.

Table 5. Region clustering according to productivity

\begin{tabular}{ccc}
\hline $\begin{array}{c}\text { Low-Productive } \\
\text { regions }\end{array}$ & Medium-Productive regions & $\begin{array}{c}\text { High-Productive } \\
\text { regions }\end{array}$ \\
\hline Piauí & Tocantins & Mato Grosso \\
Maranhão & Goiás & Rondônia \\
Ceará & Pará & Santa Catarina \\
Paraíba & Mato Grosso do Sul & Espírito Santo \\
Alagoas & Minas Gerais & Rio Grande do Sul \\
Rio Grande do Norte & Acre & Amazonas \\
Bahia & Amapá & Rio de Janeiro \\
Pernambuco & Paraná & São Paulo \\
Sergipe & Roraima & Distrito Federal \\
\hline
\end{tabular}

Source: Author's elaboration 


\section{Figure 1. Gross value added per worker in Brazilian states}

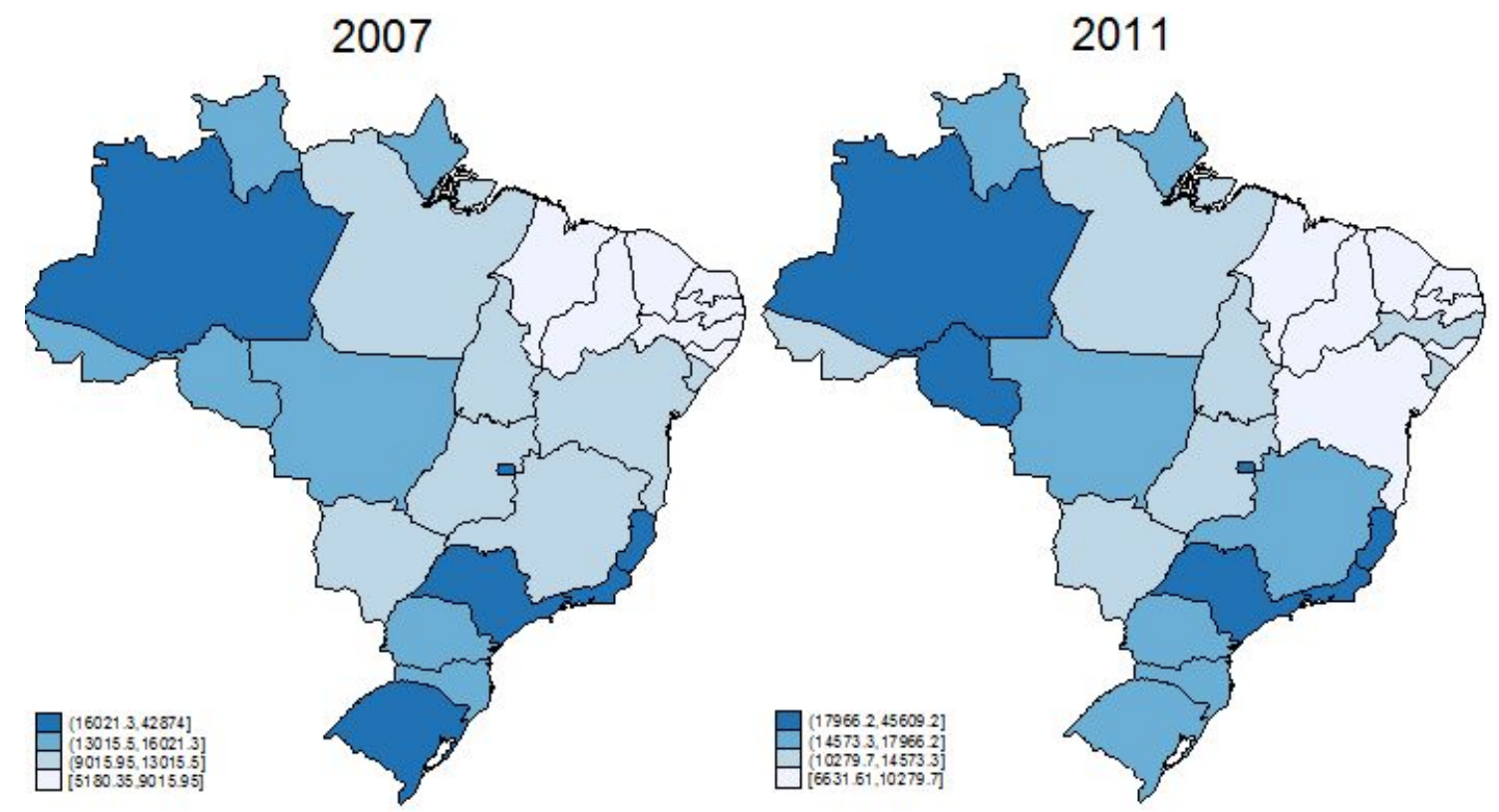

Source: Author's analysis from the databases described above.

Figure 2. Broadband across Brazilian states
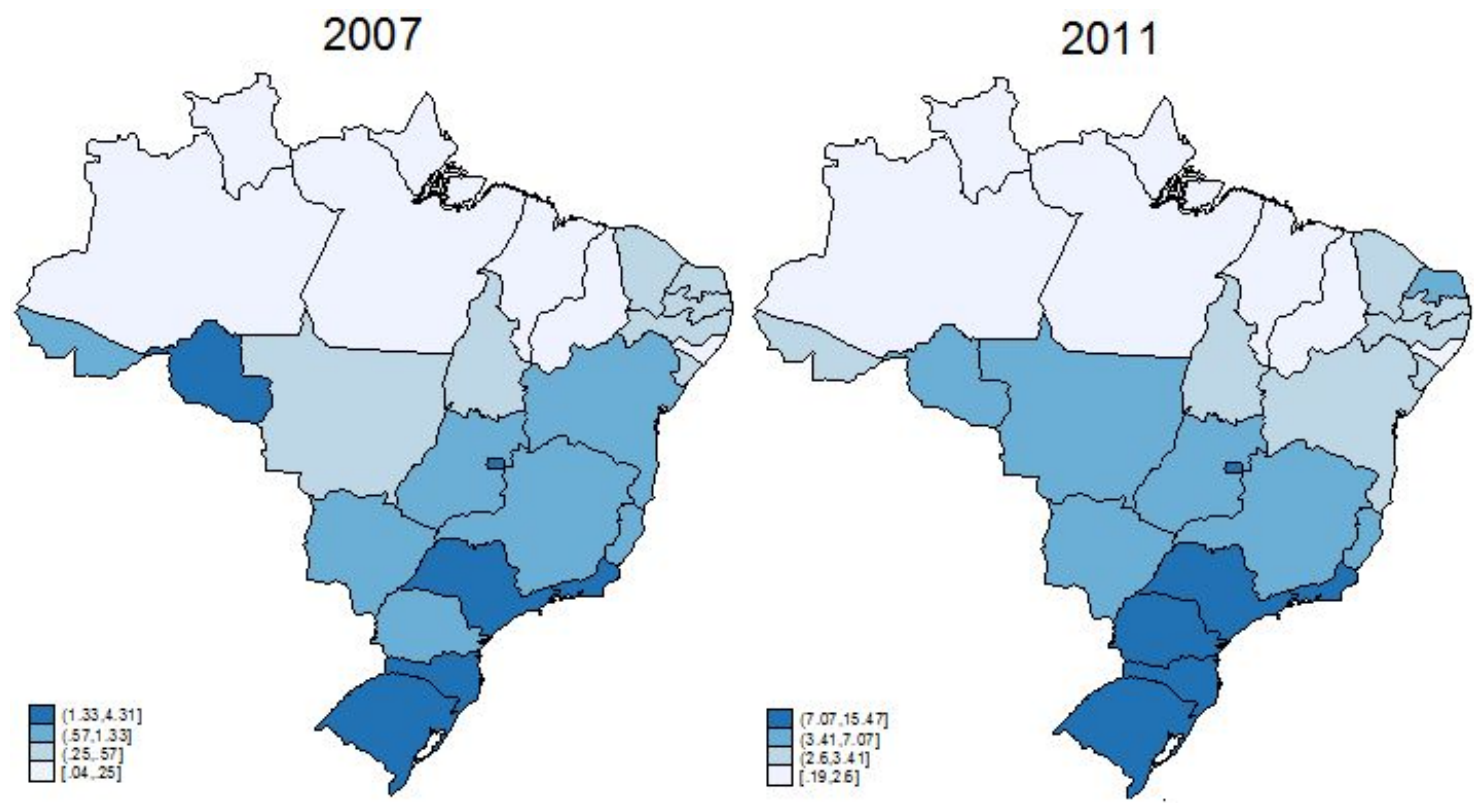

Source: Author's analysis from the databases described above. 
Figure 3. Productivity and broadband in the Brazilian states
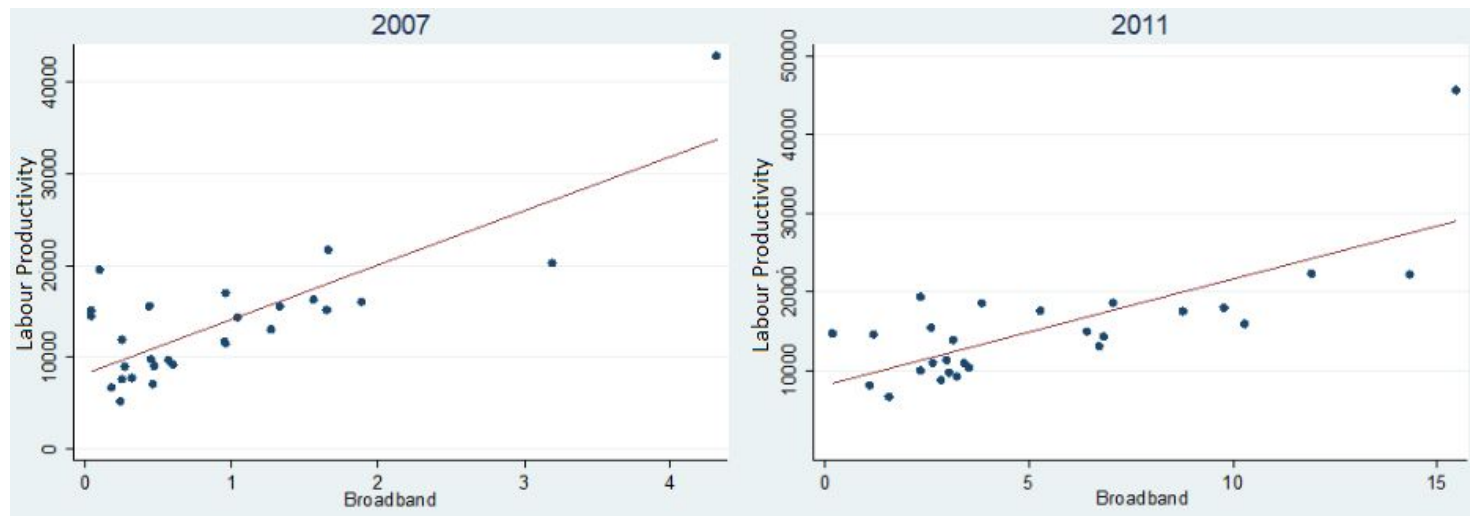

Source: Author's analysis from the databases described above. 


\section{Appendix}

Table A.1. First Stage estimations

\begin{tabular}{|c|c|c|}
\hline $\begin{array}{l}\text { Dependent variable: } \\
\log (\text { Broadband })\end{array}$ & $\begin{array}{l}\text { First Stage for Column } \\
\text { (iii) in Table } 3 \\
\end{array}$ & $\begin{array}{l}\text { First Stage for Column } \\
\text { (iv) in Table } 3 \\
\end{array}$ \\
\hline $\begin{array}{l}\text { Fixed Telephone lines per } 100 \\
\text { inhabitants (5-year lag) }\end{array}$ & $\begin{array}{c}-0.369^{* * *} \\
{[0.037]}\end{array}$ & $\begin{array}{c}-0.369^{* * *} \\
{[0.036]}\end{array}$ \\
\hline Population density (1920-1950) & $\begin{array}{c}0.009 * * * \\
{[0.003]}\end{array}$ & $\begin{array}{c}0.010^{* * *} \\
{[0.003]}\end{array}$ \\
\hline Literacy rate & $\begin{array}{c}0.212 * * * \\
{[0.039]}\end{array}$ & $\begin{array}{c}0.201 * * * \\
{[0.051]}\end{array}$ \\
\hline Public R\&D intensity & $\begin{array}{c}2.229 \\
{[1.604]}\end{array}$ & $\begin{array}{c}2.306 \\
{[1.633]}\end{array}$ \\
\hline Imports & $\begin{array}{c}0.701 \\
{[3.007]}\end{array}$ & $\begin{array}{c}0.937 \\
{[3.356]}\end{array}$ \\
\hline Services & & $\begin{array}{l}-1.920 \\
{[3.212]}\end{array}$ \\
\hline Agriculture & & $\begin{array}{l}-2.439 \\
{[4.802]}\end{array}$ \\
\hline Unemployment & & $\begin{array}{c}0.011 \\
{[0.048]}\end{array}$ \\
\hline Test $F$ of excluded instruments: & $62.18 * * *$ & $60.24 * * *$ \\
\hline
\end{tabular}

First step estimates denoted in Table A.1 confirm the relevance of the proposed instruments to explain broadband adoption. In both estimates, significance levels of $1 \%$ are reached for the individual and joint tests of significance of the coefficients of both instruments. While the overall correlation in the sample between the 5-year lag of the fixed telephone lines per 100 inhabitants and (the $\log$ of) Broadband is positive (0.181), the negative sign in Table A.1 is due to the control of the region fixed effects. In this case, the respective coefficients only capture the within variation, that is, the one due to changes over time. Therefore, the negative coefficient for the fixed telephone lines indicate that broadband adoption may have grown more rapidly in regions with lower initial endowments of the older infraestructures. 
Table A.2. Estimation of the Broadband effect in each region.

\begin{tabular}{|c|c|c|c|}
\hline & Share Labour & Share Capital & Effect of BB \\
\hline Brasil & 0.42 & 0.58 & 0.013 \\
\hline Rondônia & 0.49 & 0.51 & 0.015 \\
\hline Acre & 0.51 & 0.49 & 0.015 \\
\hline Amazonas & 0.37 & 0.63 & 0.011 \\
\hline Roraima & 0.58 & 0.42 & 0.017 \\
\hline Pará & 0.37 & 0.63 & 0.011 \\
\hline Amapá & 0.59 & 0.41 & 0.018 \\
\hline Tocantins & 0.48 & 0.52 & 0.014 \\
\hline Maranhão & 0.43 & 0.57 & 0.013 \\
\hline Piauí & 0.49 & 0.51 & 0.015 \\
\hline Ceará & 0.45 & 0.55 & 0.014 \\
\hline Rio Grande do Norte & 0.48 & 0.52 & 0.014 \\
\hline Paraíba & 0.50 & 0.50 & 0.015 \\
\hline Pernambuco & 0.47 & 0.53 & 0.014 \\
\hline Alagoas & 0.48 & 0.52 & 0.015 \\
\hline Sergipe & 0.46 & 0.54 & 0.014 \\
\hline Bahia & 0.44 & 0.56 & 0.013 \\
\hline Minas Gerais & 0.41 & 0.59 & 0.012 \\
\hline Espírito Santo & 0.33 & 0.67 & 0.010 \\
\hline Rio de Janeiro & 0.41 & 0.59 & 0.012 \\
\hline São Paulo & 0.41 & 0.59 & 0.012 \\
\hline Paraná & 0.39 & 0.61 & 0.012 \\
\hline Santa Catarina & 0.40 & 0.60 & 0.012 \\
\hline Rio Grande do Sul & 0.41 & 0.59 & 0.012 \\
\hline Mato Grosso do Sul & 0.40 & 0.60 & 0.012 \\
\hline Mato Grosso & 0.38 & 0.62 & 0.012 \\
\hline Goiás & 0.39 & 0.61 & 0.012 \\
\hline Distrito Federal & 0.54 & 0.46 & 0.016 \\
\hline
\end{tabular}

Note: Data used to compute the labour and capital share in gross domestic product from Contas Regionais do Brasil. The effect of Broadband uses the IV estimate of the corresponding coefficient in Table 3. 
Table A.3. Additional variables used in the empirical analysis

\begin{tabular}{llcccc}
\hline Variable & \multicolumn{1}{c}{ Definition } & Source & Mean & s.d. & Min-Max \\
\hline Mass & $\begin{array}{l}\text { Dummy variable which takes value of } \\
\text { 1 if } \text { Broadband }>0.06\end{array}$ & Telebrasil & 0.156 & 0.364 & $0-1$ \\
Quality & $\begin{array}{l}\text { Weighted average broadband speed in } \\
\text { Mbps }\end{array}$ & Telebrasil & 4.415 & 2.819 & $1.316-13.828$ \\
\hline
\end{tabular}

Source: Author's elaboration

Figure A.1. Average fixed broadband download speed across Brazilian states

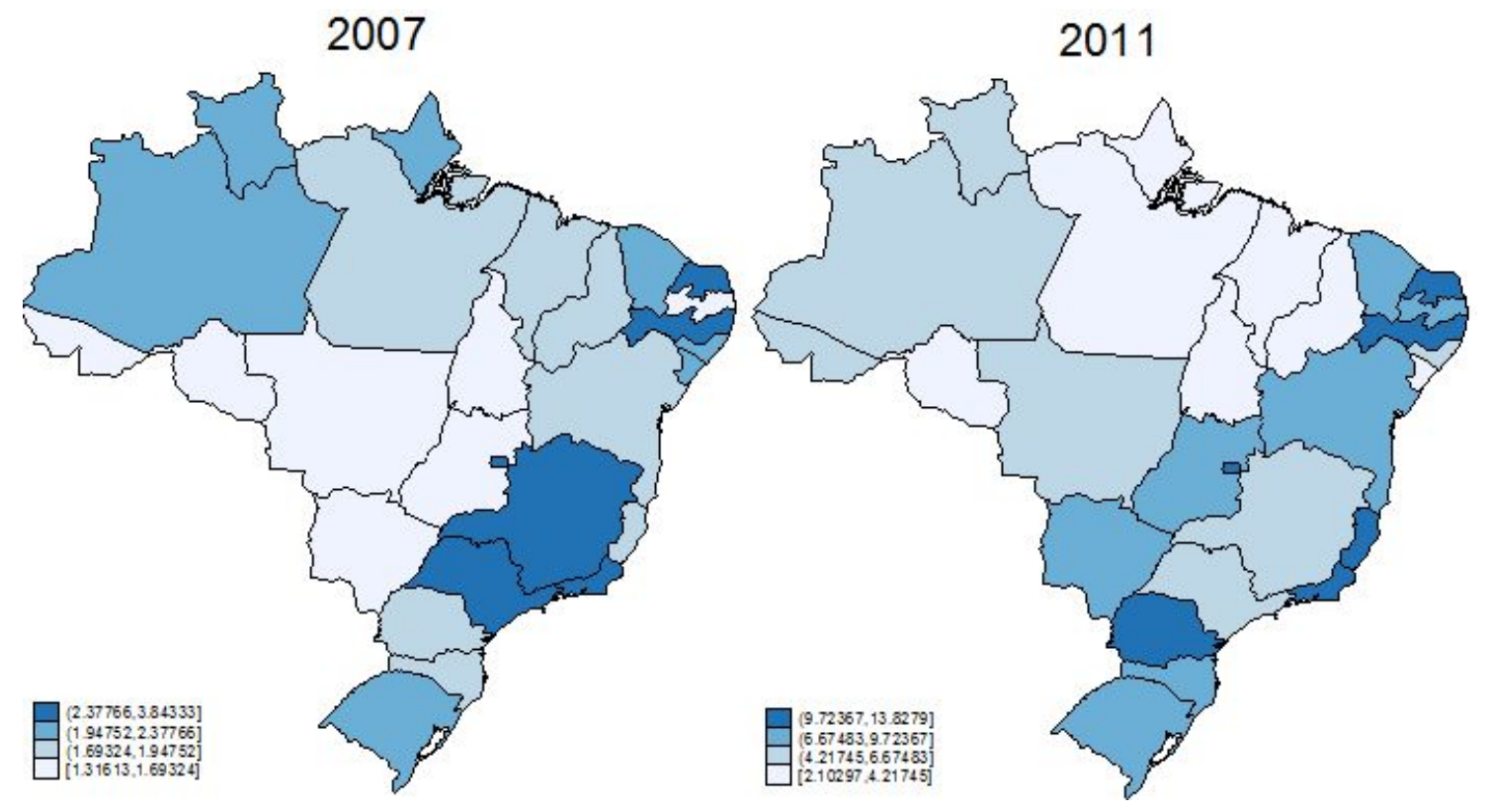

Source: Author's analysis from the databases described above. 


\section{$\underset{\oplus}{\mathbb{Q}}|\mathrm{R}| \mathrm{E}|\mathrm{A}|$}

Institut de Recerca en Economia Aplicada Regional i Públic

Research Institute of Applied Economics

WEBSITE: www.ub-irea.com • CONTACT: irea@ub.edu

\section{AQR}

Grup de Recerca Anàlisi Quantitativa Regional

Regional Quantitative Analysis Research Group

WEBSITE: www.ub.edu/aqr/•CONTACT: aqr@ub.edu

\section{Universitat de Barcelona}

Av. Diagonal, 690 • 08034 Barcelona 